\title{
Lucha por la vivienda y politización de las trayectorias individuales*
}

\author{
Nicolás Angelcos Gutiérrez \\ École des Hautes Études en Sciences Sociales, París, Francia. \\ Email: nicolas.angelcos@ehess.fr
}

\begin{abstract}
Resumen: El presente artículo busca interrogar las formas y mecanismos que adoptan los procesos de politización en los sectores populares chilenos. Para ello, se analiza el caso del comité de vivienda "MPL- Franklin"1 organizado semanas después del pasado terremoto del 27 de Febrero del 2010. La tesis que se desarrolla versa sobre la necesidad de problematizar la relación entre subjetivación individual y subjetivación colectiva para comprender la politización de las demandas, en principio instrumentales, que articula el movimiento. A partir del concepto de "afección política" se intenta reconstruir el vínculo entre la lucha por la vivienda y las trayectorias individuales de los vecinos miembros del comité. Las preguntas de investigación son las siguientes: ¿cómo se puede explicar la politización de ciertos individuos en un medio social donde la pasividad reina?; ¿cómo se puede comprender la afección de ciertos individuos por la política de cara a una desafección generalizada?
\end{abstract}

Palabras clave: subjetivación, politización, vivienda.

\section{Struggle for housing and politicization of individual trajectories}

\begin{abstract}
This article seeks to examine the ways and mechanisms adopted by the processes of politicization in the popular sectors in Chile. To this end, we analyze the case of the housing committee "MPL-Franklin" created weeks after the last earthquake of February 27, 2010. The thesis developed concerns the need to problematize the relationship between individual subjectivity and collective subjectivity to understand the politicization of demands, instrumental at first, which coordinate the movement. The concept of "political affection" is used to rebuild the link between the struggle for housing and the individual trajectories of the committee members. The research questions are: how the politicization of certain individuals in a social environment where passivity reigns can be explained?; How can we understand the affection of some individuals in politics, in a setting of general disaffection?
\end{abstract}

Key words: subjectification, politicization, housing.

\section{Luta por moradia e politização das trajetórias individuais}

Resumo: Este artigo procura analisar as formas e os mecanismos a adoptar nos processos de politização dos setores populares no Chile. Para isso, analisamos o caso da comissão da habitação "MPL-Franklin", organizado na semana passada após o terremoto de 27 de fevereiro de 2010. A tese que é desenvolvida aborda a necessidade de problematizar a relação entre subjetivação individual e subjetivação coletiva para entender a politização das demandas, em princípio, instrumentais, que coordena o movimento. Usando o conceito de "condição política" destina-se a reconstruir a ligação entre a luta pela habitação e as trajetórias individuais dos membros da comissão de vizinhos. As questões de pesquisa são: como explicar a politização de certos indivíduos em um ambiente social onde rainha a passividade? como se pode compreender a afeição de certos indivíduos pela política entre um descontentamento generalizado?

Palavras-chave: subjetivação, politização, habitação.

$$
* * *
$$

\section{Introducción}

El 27 de Febrero del año 2011 se conmemoró un año de la tragedia que sacudió el centro- sur de nuestro país. Si bien la catástrofe natural que implicó el terremoto era en gran medida inevitable, para nadie resulta extraño que la gestión política de sus consecuencias haya sido completamente ineficaz ${ }^{2}$. Así, nos parece insuficiente hablar de una catástrofe natural cuando diversos factores sociales y políticos nos hablan de una crisis social de bastante mayor alcance. 
El terremoto develó diversas aristas en la construcción del orden social chileno. Por una parte, un número elevado de personas -sin ningún antecedente delictivo- salió a la calle y, en conjunto, protagonizó verdaderos pillajes en distintos centros comerciales. Por otro lado, la población "normalizada" y los medios de comunicación organizaron una activa respuesta. Los vecinos, movilizados por un temor difícilmente explicable, se articularon para conformar patrullas ciudadanas en los márgenes de sus poblaciones, cuidando aquellos bienes que parecían amenazados por la turba. Por su parte, los medios de comunicación, aparte de instalar el miedo entre la población, efectuaron una fuerte condena moral hacia aquellos individuos implicados en los saqueos, arguyendo su carácter excesivo, o sea, que rompe con los límites de lo necesario.

Este panorama ya nos muestra una triple cara del orden social chileno. Unos, ante la imposibilidad de acceder a bienes materiales lujosos (televisores de plasma u otros), se aprovechan del caos que siguió al terremoto y roban. Otros, más leales con la propiedad y las normas, se arman dispuestos a defender con violencia lo que les pertenece. Ellos, establecen el límite entre lo lícito y lo ilícito, lo moral y lo inmoral. Las tres caras, sin embargo, muestran la misma importancia de los bienes materiales en la construcción de la identidad personal y el carácter absolutamente privado de esa construcción. Frente a esto, saqueadores, patrullas ciudadanas y medios de comunicación no vacilan en saltarse los canales formales que nuestro sistema democrático ha definido para legitimar el orden social, ya sea robando, golpeando o llamando a los militares.

Ahora bien, el terremoto ha develado otra cara de nuestra sociedad. La reconstrucción material y social aún en curso muestra cómo la "sanción normalizadora" actúa hacia aquéllos que burlan la propiedad privada, base del modelo, pero no para aquéllos que lo sostienen, para quienes normalizan. El tema de la vivienda ha sido particularmente sensible a este respecto.

El déficit habitacional en Chile alcanzaba a 543 mil unidades hasta el año 2010. Si bien durante los veinte años de gobierno de la Concertación se redujo a casi la mitad el número de familias sin casa, el déficit nunca dejó de ser preocupante, esto sin contar la calidad y ubicación de las nuevas viviendas sociales. Post terremoto esta cifra subió a 900 mil casas (Zúniga, 2010) tornando el problema habitacional alarmante y evidenciando la ineficacia de las políticas de vivienda llevadas a cabo por la Concertación, donde se articulaba la subvención estatal, con el ahorro privado y la construcción entregada a las empresas inmobiliarias.

El gobierno de Sebastián Piñera no lo ha hecho mejor. Por una parte, ha sido incapaz de resolver el problema de la reconstrucción, sobre todo para aquéllos que no eran propietarios antes del terremoto, fueran allegados o arrendatarios permanentes. Por otra parte, ante una supuesta ineficiencia en la asignación y focalización de los recursos públicos, se intenta reformar las políticas de vivienda anteriores, reduciendo el Fondo Solidario 1 (ahorro mínimo 10 U.F.), correspondiente a las familias más pobres. Con ello, se busca subrayar la necesidad de un mayor ahorro privado (Fondo Solidario 2, ahorro mínimo 30 U.F.) y la disminución de los gastos públicos en subsidios (Ministerio de Vivienda y Urbanismo, 2010).

Si a esto le agregamos la intención de terminar con las EGIS (Entidad de Gestión Inmobiliaria), es decir, con las formas colectivas de postulación a subsidios, y la eliminación del subsidio de interés territorial, cuestión que haría imposible la adquisición de una vivienda social en la comuna actual de residencia, la fragmentación y segregación social podrían agudizarse de forma dramática.

Harloe (Desjardins, 2008) distingue dos modelos de políticas de vivienda social, a saber: el modelo de masa y el modelo residual. El primero refiere a la concepción de la vivienda en tanto beneficio universal otorgado a las clases trabajadoras como participantes activas del contrato social; el segundo, por su parte, está dirigido a los sectores más pobres y opera a partir de una descentralización de la gestión y el financiamiento. Siguiendo esta distinción, el modelo chileno busca profundizar la política de vivienda residual, cuyos costos sociales son enormes: "en el modelo residual, el sector social es estigmatizado porque concentra a los grupos marginalizados, políticamente, económicamente y socialmente" (Desjardins, 2008: 32-33).

Todas estas aristas hacen del problema de la vivienda un asunto extremadamente complejo. El movimiento de deudores habitacionales que ha constituido la cara más visible de este conflicto debiera, de esta forma, ser capaz de articular la lucha por la condonación de las deudas, con la permanencia territorial, la 
aumentación del Fondo Solidario 1, la necesidad de la postulación colectiva, la lucha contra la exclusión, etc. Esta complejidad explica una gran parte de las constantes divisiones y reagrupaciones del movimiento.

Ahora bien, como hemos querido enfatizar, la crisis social que siguió al terremoto puso en tela de juicio ciertos consensos normativos en torno a la legitimidad del "modelo chileno". Primero, mostró que la estabilidad de nuestro orden está expuesta a una fragmentación súbita en el caso de enfrentarse a una nueva "crisis". Segundo, la credibilidad del empresariado chileno quedó en entredicho cuando construcciones pertenecientes a la clase media se derrumbaron, aún cuando su costo era elevado. Finalmente, el gobierno y la política en general se revelaron una vez más estar completamente distanciados de las necesidades del mundo popular. Frente a este escenario, el problema de la vivienda y la capacidad de respuesta de los actores sociales es un asunto de vital relevancia.

En este marco, nuestra investigación intenta comprender el proceso de politización que vivió un grupo de habitantes "sin techo" del barrio Franklin de Santiago. Esta politización comprende diversas etapas: 1) la inscripción en el comité de vivienda formado por el "Movimiento de Pobladores en Lucha"; 2) la participación regular en éste; y 3) la incorporación militante en el movimiento. La particularidad de este comité es que nace como consecuencia del terremoto y es conformado por vecinos y vecinas sin ningún capital político anterior. Quisiéramos mostrar en esta ponencia, a partir del análisis de este comité, cómo la política "afecta" la identidad de los individuos involucrados y de qué forma esto determina el devenir de la organización.

\section{Insensibilidad de lo público. De la demanda democrática a la demanda popular}

Acaecido el terremoto el 27 de Febrero del año 2010 y “superados" los impasses provocados por los saqueos y la respuesta militar, comenzó el difícil proceso de reconstrucción material y social de nuestro país. La comuna de Santiago, al igual que las demás comunas, fue elaborando un catastro de los sectores y construcciones más afectados, intentando dar una pronta solución a las víctimas. Para ello, se constituyeron comités de reconstrucción que actuaron como mediadores entre las autoridades municipales y los vecinos afectados.

En este proceso, sin embargo, se llamó a participar solamente a los propietarios ${ }^{3}$. De este modo, allegados y arrendatarios de la comuna debieron resignarse ante una ayuda estatal y diseñar, en la medida de lo posible, alguna estrategia individual que les permitiera enfrentar la difícil situación que estaban viviendo. En este marco, el Movimiento de Pobladores en Lucha, cuyo mayor trabajo político está situado en Peñalolén ${ }^{4}$, organizó un comité de reconstrucción en el histórico barrio Franklin para aquellos olvidados por las autoridades, intentando ofrecer una dinámica de trabajo colectivo como herramienta de lucha en la demanda por una vivienda.

Al entrevistar a varios miembros del comité (principalmente mujeres), ellas muestran cómo la elección de inscribirse en él fue el resultado de la situación problemática en que vivían dada la falta de casa (anterior al terremoto) y la oferta propuesta por el movimiento. El MPL les relató la experiencia de lucha que vienen desarrollando hace varios años en Peñalolén y los resultados que han obtenido (dos soluciones habitacionales ${ }^{5}$ ) en dicha comuna. El terremoto, en este sentido fue la excusa para que, demandas ya existentes pero desarticuladas, se organizaran alrededor de un comité y formaran una demanda colectiva.

En términos de Ernesto Laclau, nosotros podemos interpretar este proceso como el paso de una demanda democrática a una demanda popular. Para Laclau, una demanda democrática es aquélla que "satisfecha o no, permanece aislada (...) ¿aisladas de qué? Sólo con respecto al proceso equivalencial (...) una demanda que se satisface no permanece aislada; se inscribe en una totalidad institucional diferencial" (Laclau, 2010: 99-103). Esta paradoja significa que una demanda al ser satisfecha no se inscribe dentro del conjunto de demandas que conforman una articulación hegemónica; por ello, permanece aislada de las demás demandas, pero integrada en la institucionalidad vigente.

La reducción del déficit de vivienda durante los veinte años de gobierno de la Concertación se inscribe en esta dinámica. Demandas por vivienda, fruto de la reorganización espacial que realizó la dictadura en la 
ciudad de Santiago, fueron satisfechas mediante la asignación de subsidios individuales para la compra de casas nuevas o usadas en los márgenes de la capital, continuando así la erradicación de los "sin casa" hacia la periferia de la ciudad, esta vez bajo la racionalidad del mercado.

Dado que la política de vivienda articula subsidios públicos con ahorro privado esta forma "democrática" de satisfacción de las demandas tiene su límite, en la medida que no todas las personas son capaces de ahorrar el dinero suficiente para optar a un subsidio. Al mismo tiempo, éstos son limitados y no tienen una cobertura universal.

Frente a esta "insensibilidad" de la institucionalidad política respecto a la demanda por vivienda de un número considerable de familias, los vecinos del barrio Franklin construyen, voluntariamente o no, una demanda colectiva de carácter popular, es decir, que articula distintos elementos correspondientes a las distintas necesidades. "A la pluralidad de demandas que, a través de su articulación equivalencial, constituyen una subjetividad más amplia, las denominaremos demandas populares” (Laclau, 2010: 99).

Así, la "demanda democrática" por vivienda, se transformó al interior del comité en una "demanda popular" por una vivienda digna, lo que significó la articulación de diversas demandas, a saber: una vivienda cuyo tamaño excede los límites de la vivienda social; una solución habitacional colectiva; y la permanencia en la comuna.

\section{Biografía individual y lucha colectiva por la vivienda digna}

Al entrevistar a algunos miembros, principalmente mujeres jóvenes (25- 36 años), del comité de vivienda pudimos integrar en nuestro análisis los principales rasgos biográficos que determinan su vida "carente" en dónde se inserta el problema de la casa propia.

Ante una pregunta abierta sobre sus historias de vida, la mayor parte de las entrevistadas iniciaba su relato con la descripción de algún padecimiento. Los principales problemas individuales registrados fueron: alcoholismo del padre o cónyuge, drogadicción de algún miembro de la familia, incapacidad de formar una familia propia, hacinamiento, problemas de relación con las personas que los acogen (en general la familia de uno de los cónyuges), enfermedad de un hijo, depresión, etc. A continuación un ejemplo:

"Yo pienso que el problema de mis hijos, lo nervioso que son, lo inquietos, proviene todo de mi condición de allegada. Porque ya es un niño que necesita su metro cuadrado para él solo y es el único hombre entre tres hermanas, entonces él se siente siempre compitiendo con ellas, siempre está como compitiendo por el espacio con sus hermanas. Es por eso que necesito irme de aquí, porque estamos muy mal, muy mal, está todo amontonado porque no tenemos espacio, en mi pieza dormimos los seis. Yo hace poquito me hice el esfuerzo de mandar a hacer un camarote de tres pisos porque ya no podía. Yo prácticamente no tenía donde dormir, yo dormía casi a los pies de la cama estirada y, gracias a eso que pudimos hacer ahora, duermen mis tres niños más grandes en el camarote y mi guagüita nomás duerme con nosotros en la cama de dos plazas." (María, 36 años, MPL Franklin)

Estos distintos elementos mencionados actuaban en sus relatos como un trauma, es decir, como la fijación inconsciente en un acontecimiento determinante para el conjunto de su biografía individual (Freud, 1965). La lucha por una vivienda digna, en este sentido, cobra el significado de una solución, no solamente material, sino, por sobre todo, al "ser-deficiente" que los define. "La plenitud de la comunidad es precisamente el reverso imaginario de una situación vivida como ser deficiente" (Laclau, 2010: 113). Su realización personal, que nunca es estrictamente individual, está íntimamente ligada a la obtención de la casa y, en sus relatos, explica su participación regular en el comité, pese a las constantes dudas y decepciones que confiesan, incluso respecto a familiares suyos que también participan.

Teniendo en cuenta los postulados teóricos de Axel Honneth, podríamos decir que la lucha por la vivienda es una lucha por el reconocimiento individual en un espacio colectivo. "Es a través de las luchas que los grupos sociales se libran en función de móviles morales, es por su tentativa colectiva por promover en el espacio institucional y cultural formas más amplias de reconocimiento mutuo que se opera en práctica la 
transformación normativa de las sociedades" (Honneth, 2010: 114). Esto no significa que la demanda sea cultural y no social, sino que la demanda social "afecta" la identidad del individuo. Así, entendemos el carácter libidinal del lazo social que une al individuo con el colectivo y la construcción de la demanda popular.

En consonancia con los planteamientos de Chantal Mouffe (2007) y Ernesto Laclau (2010) llamaremos "afección política" a la articulación entre la identidad individual y la estructuración subjetiva de la comunidad que comporta el comité. "El objeto de la investidura puede ser contingente, pero ciertamente no es indiferente, no puede ser cambiado a voluntad. Con esto logramos una explicación completa de lo que significa investidura radical: el hacer de un objeto mítico la encarnación de una plenitud mítica. El afecto (es decir, el goce) constituye la esencia misma de la investidura, mientras que su carácter contingente da cuenta del componente "radical" de la fórmula (Laclau, 2010: 148).

El trauma constituyente de la subjetividad individual puede ser interpretado así como un sentimiento pre- político y síntoma de un reconocimiento erróneo, donde los obstáculos materiales cobran una profunda relevancia en la biografía individual y familiar. "Todas las emociones negativas suscitadas por la experiencia del desprecio de las exigencias de reconocimiento comportan, en efecto, la posibilidad de que el sujeto concernido tome claramente conciencia de la injusticia que le es cometida, y encuentre ahí un motivo de resistencia política" (Honneth, 2010: 144).

La lucha por la vivienda digna, además de articular los elementos ya reseñados, permite la elaboración de una semántica compartida, una gramática moral del conflicto, tal cual lo entienden E.P. Thompson (1971) y Axel Honneth. "Entre los objetivos impersonales de un movimiento social y las ofensas privadas sufridas por los individuos que lo componen, debe existir una pasarela semántica lo suficientemente sólida para permitir el desarrollo de una identidad colectiva" (Honneth, 2010: 195).

De este modo la demanda por la vivienda y la participación en el comité, en principio, instrumentales, se transforman en compromisos morales donde la identidad de los individuos se encuentra totalmente implicada ${ }^{6}$. La subjetivación política implica así una articulación, en permanente tensión, entre la identidad y biografía individual con la construcción de una comunidad de pertenencia.

Llamaremos subjetivación política individual a los "procesos de auto-transformación llevados a cabo por las propias personas. Cada uno es, desde este punto de vista, el actor o el autor, o el sujeto de su propia subjetivación" (Wieviorka, 2008: 39). El deseo de conducir su propia vida significa para el sujeto "el llamado a valores y la definición de obstáculos para su cumplimiento. El pasado, la dominación y el orden obstaculizan la realización de ese sujeto (...) La toma de distancia crítica implica una adhesión previa, el retorno de los valores proclamados contra el orden de cosas" (Dubet, 1994: 148- 149).

La subjetivación política colectiva será entendida como "la producción mediante una serie de actos de una instancia y de una capacidad de enunciación que no eran identificables en un campo de experiencia dado, así la identificación va de la mano con la reconfiguración del campo de la experiencia" (Rancière, 2007: 59). Rancière intenta mostrar cómo la construcción de una identidad colectiva implica necesariamente una subversión respecto a las condiciones de posibilidad de la experiencia, en la medida que la estructuración de una nueva identidad necesita un nuevo campo sensible de inscripción. En términos de Laclau, las demandas populares, al articularse en un proyecto contra-hegemónico, son significadas al interior de una comunidad mítica, antagónica a la totalidad institucional diferencial que define a las demandas democráticas.

\section{De la gramática moral a la pragmática política del conflicto}

Hasta el momento hemos podido evidenciar una participación instrumental y moral en el comité de vivienda, sin embargo, aún nos falta descifrar su contenido político.

En la mayor parte de las entrevistas realizadas, incluso en militantes del MPL ajenos al comité que llevan años en la lucha por sus viviendas en Peñalolén, los individuos se declaran apolíticos. Esto significa varias cosas, según las razones esgrimidas por los mismos actores: primero, no se sienten identificados con 
ningún partido político, ni de izquierda ni de derecha, es más, el clivaje izquierda-derecha no los interpela en lo más mínimo; segundo, ven a la institucionalidad política como algo excesivamente lejano, tal como la realidad lo indica, insensible a sus demandas e inquietudes; tercero, por el mismo motivo anterior, un cambio de gobierno les es casi indiferente, de hecho, la mayoría no están inscritos en los registros electorales. En síntesis, están completamente distanciados de la política institucional.

"Sea el presidente que haya que se ponga, a las finales igual uno tiene que sacrificarse pa" tener sus gastos" (Claudia, 34 años, MPL Franklin).

Esta constatación empírica parece respaldar la tesis general acerca de la apatía, la desafección política o la despolitización de la sociedad chilena. Muchos autores dan cuenta de este fenómeno, poniendo especial énfasis en el desinterés que suscita la política en aquellos jóvenes y adultos que pertenecen a la generación post-plebiscito, es decir, que no participaron en el plebiscito de 1988 (Aranda y Cuevas, 2008; Baño, 1995; González, et. al., 2005; Ruz, 2008; Toro, 2008).

A partir de lo siguiente, no quisiéramos desmentir esa tesis, simplemente nos gustaría mostrar cómo las actividades que se realizan al interior del comité implican una práctica política, consciente aunque no enunciada. El comité Franklin se reúne una vez a la semana en la sede de la junta de vecinos. En dichas reuniones, se dan distintas dinámicas. En algunas hay espacios para el esparcimiento, desde la elaboración o realización de rifas hasta la venta y consumo de alimentos; si bien el objetivo de estas actividades es recaudar dinero (objetivo instrumental) también permiten la conformación de una comunidad (objetivo cultural). Más allá de estas actividades, en todas las reuniones el presidente del comité (vecino del barrio) y un representante del MPL de Peñalolén dan cuenta de los avances de la lucha y los nuevos objetivos a perseguir; al mismo tiempo, uno o dos representantes de cada comisión formada (comunicación externa e interna, búsqueda de terrenos, contactos con el municipio, tesorería, etc.) hacen un reporte de sus acciones. En tres reuniones que participamos, fueron representantes de la política institucional, contactados directamente por el presidente de la junta de vecinos, dos concejales (UDI y PPD) ${ }^{7}$ y un diputado del distrito (PPD). Asimismo, asistimos junto a los vecinos a una sesión del concejo municipal donde los concejales invitados a las reuniones, además de la concejala comunista, pusieron en el debate el problema de allegamiento de los vecinos del comité.

También, la mayor parte de los vecinos acude a las manifestaciones de la Federación Nacional de Pobladores, de la cual el MPL es parte. En fin, entre reuniones, relaciones con el municipio, contactos con autoridades políticas, manifestaciones, etc., los vecinos van adquiriendo un capital político que no poseían. Pese a que ellos no vean en el movimiento un ente político, se declaren incompetentes en política, la dinámica de la lucha les lleva inevitablemente a un accionar político. De hecho, algunos miembros nos declararon su deseo de transmitir ese capital adquirido a personas que estén en la misma situación de carencia que ellos.

"Yo creo que es por el objetivo que es el de la casa y de vivir dignamente, como dicen los chiquillos, pero si se necesitaran o alguna persona necesitara un consejo o algo, yo podría hacer lo mismo que hicieron conmigo. Explicarles y guiarlos sobre cómo hacerlo" (Patricia, 33 años, MPL Franklin).

En consecuencia, la pragmática política en la que se ven envueltos los miembros del comité nos permite descentrar la reflexión sociológica de la política respecto a su manifestación estrictamente institucional (Angelcos, 2010a; 2010b; 2011). La política llevada a cabo por el comité es el resultado de la articulación de sentimientos pre-políticos individuales, con una semántica moral compartida al interior del comité y una cierta orientación práctica de parte de los miembros del MPL. A continuación, mostraremos cómo los dirigentes buscan construir una ideología que permita darle una enunciación política a esta pragmática y cómo esto tiene repercusiones en la construcción identitaria de los individuos participantes.

\section{Vida digna y politización de las trayectorias individuales}

Un elemento central en el proceso de politización que estamos describiendo es la "ideología" con la cual el MPL busca interpelar la subjetividad de los individuos insertos en el comité. Tal cual como ellos lo definen, la "vida digna" es el horizonte político hacia el cual apuntan las distintas demandas populares elaboradas. "La vida digna no es vivir mejor que otros o vivir mejor que antes, sino una opción que se 
expresa en el reconocimiento del comportamiento, de la diversidad y de la experiencia de vida de nuestros pueblos. Esta no representa un ideal externo, sino un horizonte construido desde la propia gente, de sus sueños, deseos y anhelos de vivir bien” (Movimiento de pobladores en lucha, 2009).

El concepto de "vida digna", elaborado por el movimiento, funciona como un "significante vacío". "Cualquier identidad popular requiere ser condensada, como sabemos, en torno a algunos significantes (palabras, imágenes) que se refieren a la cadena equivalencial como totalidad. Cuanto más extendida es la cadena, menos ligados van a estar estos significantes a sus demandas particulares originales. Es decir, la función de representar la "universalidad" relativa de la cadena va a prevalecer sobre la de expresar el reclamo particular que constituye el material que sostiene esa función” (Laclau, 2010: 125). Vida digna es una totalidad que "constituye un horizonte y no un fundamento" (Laclau, 2010: 95) de la acción colectiva.

$\mathrm{Al}$ entrevistar a los participantes del comité y preguntarles por la idea de vida digna, la gran mayoría tuvo la capacidad de definir, aun sin rigurosidad, a qué es lo que se refería el movimiento. Lo particular de esto es que prácticamente todas las definiciones fueron distintas, en relación a los problemas y traumas desde los cuales los individuos narraban sus vidas. En este sentido, la vida digna era aquel lugar donde las distintas expectativas individuales encontrarían un espacio o margen de realización. Si bien la vivienda constituía un elemento central en la definición que los participantes del comité hacían respecto a la vida digna, la totalidad en la cual ésta se inscribía sobrepasaba ampliamente los límites de la vivienda.

"Nosotros estamos en un primer plano peleando, luchando por la vivienda digna, pero más allá de la vivienda digna, hay algo que es más importante, que es la vida digna. Porque la vivienda digna, claro, tendrá 4 paredes, tendrá techo, tendrá una ventanita pa' mirar, tendrá un patio con algunas plantitas, pero eso no hace una vida digna, la vida digna la hace esto que estamos haciendo nosotros, juntarnos, organizarnos y luchar porque seamos una mejor sociedad, eso es digno. Si al final, la casa es lo de menos. Bueno, yo tengo 57 años, quizás por eso pueda decirlo con bastante certeza, yo puedo vivir debajo de un puente y no tendría ningún problema si me tocara en un momento, eso no me va a quitar mi vida digna. Mi vida digna no nace por la vivienda, a lo mejor por medio de la vida digna puedo llegar a la vivienda, porque lo nuestro no es solamente la vivienda, la vivienda no es lo único que nos amarra: nos amarra la organización, el deseo de formar una comunidad diferente" (Héctor, 57 años, MPL Franklin)

Por esto, la politización del comité consistió, desde un punto de vista pragmático, en la creación de espacios comunitarios orientados a suplir las carencias que afectan al conjunto de los vecinos y que no se resuelven directamente en el problema de la casa. Concretamente, el movimiento generó un taller de lectura y escritura para los niños y niñas menores de diez años, realizado los días sábado fuera de las reuniones periódicas del comité. Asimismo, se intentó organizar actividades de recreación (asados, fiestas para los niños, celebraciones, etc.) que permitieran ir practicando estas nuevas relaciones sociales entre los vecinos de las cuales habla el concepto de "vida digna". Finalmente, para motivar las tareas de autogestión y combatir los problemas de cesantía que afectan al comité, el movimiento ofreció una capacitación gratuita en labores de construcción, competencias que asegurarían a los interesados trabajar en la construcción del proyecto de vivienda MPL1 en Peñalolén, previsto para principios del año 2011.

Siguiendo los planteamientos de Ernesto Laclau (2010), se puede entender la politización del comité como la asignación del nombre "vivienda" a un conjunto de demandas populares, inicialmente fragmentadas, que se articulan en la elaboración de un proyecto colectivo orientado a subvertir las condiciones de vida existentes. "Encarnar algo sólo puede significar dar un nombre a lo que está siendo encarnado; pero como lo que está siendo encarnado en una plenitud imposible, algo que carece de una consistencia independiente propia, la entidad 'encarnadora' se convierte en el objeto pleno de investidura catéctica. El objeto encarnante constituye, así, el horizonte último de aquello que es alcanzable, no porque exista un más allá, sino porque ese más allá, al no tener entidad propia, sólo puede estar presente como el exceso fantasmático de un objeto a través del cual la satisfacción puede alcanzarse" (Laclau, 2010: 152-153).

El "ser carente" que define la condición ontológica de los individuos implicados sólo podría dejar de serlo en un horizonte político llamado "vida digna". Importante de este horizonte es que la politización y articulación de las demandas implica desde ya la realización del proyecto político, en tanto se busca practicar 
aquellas relaciones buscadas. Tal cual afirma Michel Foucault, no se trata de afirmar una condición negada, sino experimentar los límites posibles de esa condición carente y construir en conjunto un nuevo "modo de vida" (Foucault, 2008).

La ideología de la "vida digna" permite interpelar la subjetividad individual de los vecinos integrándolos a un proyecto de subjetivación política colectiva, de cuya consolidación depende gran parte del éxito del comité, al menos en cuanto al problema de la vivienda. La articulación entre subjetivación individual- "deseo de ser actor" (Touraine y Khosrokhavar, 2000) -y subjetivación colectiva- "litigio por la igualdad" (Rancière, 2007)- es un problema de tamaño mayor que debe enfrentar el movimiento si busca transformar la "afección política" en militancia.

El concepto de "vida digna", dada su "vacuidad esencial", cumple el rol de traducir políticamente las demandas individuales de los distintos vecinos. En este sentido, no es una ideología "externa" a los miembros del comité, sino que se significa al "interior" de éste. La significación de la "vida digna" permite construir una relación antagónica con los actores hegemónicos de la sociedad chilena. Por ejemplo, no poder salir de la condición de allegado o superar el alcoholismo de alguno de los miembros de la familia ya no es producto de carencias privadas, cuyo ámbito de resolución es estrictamente individual.

Ahora, dichas condiciones "carentes" se enfrentan a una institucionalidad insensible respecto a las distintas dimensiones que componen la "vida digna" y que otorgan un significado colectivo a los malestares individuales. "El populismo requiere la visión dicotómica de la sociedad en dos campos -uno que se presenta a sí mismo como parte que reclama ser el todo- (...) esta dicotomía implica la división antagónica del campo social, y que el campo popular presupone, como condición de su constitución, la construcción de una identidad global a partir de la equivalencia de una pluralidad de demandas sociales" (Laclau, 2010: 110).

La "vida digna" funciona como un referente normativo de la "vida buena" (Honneth, 2006a), donde las expectativas de reconocimiento se comportan de forma contra-fáctica ante la "vida dañada" (Adorno, 2004), permitiendo realizar un ejercicio crítico sobre el estado de cosas existentes. De este ejercicio crítico y de la posibilidad de generar una semántica compartida en torno a los significados del desprecio, de los cuales hablamos anteriormente, depende, a juicio de Honneth (2010), la estructuración del conflicto social.

\section{Problemas de participación y comunicación en el comité}

A partir de las categorías de análisis que hemos empleado, podemos cruzar distintos elementos que se revelan como problemas en el funcionamiento y en la conformación de una identidad colectiva en el comité. Debemos destacar que, al momento de nacer el comité, se inscribieron alrededor de 120 familias. Sin embargo, a poco iniciado el proceso, este número se redujo drásticamente, llegando a la participación de unas 30 familias, aproximadamente un cuarto respecto a la primera inscripción. Con ello, quisiéramos mostrar que la inscripción en el comité está lejos de ser un acto político, sino más bien es una acción instrumental orientada a la obtención de una solución respecto al problema de la vivienda. De hecho, la construcción de un proceso reivindicativo de más largo alcance fue motivo suficiente para que la mayoría de las familias inscritas decidiera desertar de la lucha.

Ahora bien, el porqué algunas familias permanecieran activas en el comité y otras desertaran es un problema difícil de resolver si consideramos las demandas y las trayectorias de forma individual, sin ningún trabajo político de significación previo. Lo que sí es más posible responder es por qué una de cada cuatro familias inscritas sí decidió seguir participando. En esto las categorías hasta ahora empleadas son muy útiles y se trata de comprender la articulación de la subjetivación individual con una subjetivación política de carácter colectivo. En otras palabras, debemos ser capaces de comprender cómo las trayectorias individuales van incorporando en el proceso de lucha elementos que pertenecen al colectivo y que no definen la identidad de nadie en específico y cómo el comité de vivienda es capaz de seguir interpelando las distintas vidas personales, incorporando en la demanda por vivienda significados, en principio, ajenos a ella.

A este respecto, son dos los principales problemas identificados por los miembros del comité, a saber: la participación (subjetivación individual) y la comunicación (subjetivación colectiva). Por participación nos 
referimos a la constancia respecto a las actividades del colectivo y el sacrificio de cierta identidad individual en pos de la consecución de ciertos objetivos precisos. Por ejemplo, además de la poca constancia en la asistencia a las reuniones del comité, los miembros más activos reclaman con cierta molestia y desazón cómo, ante la necesidad de apoyar manifestaciones reivindicativas ("funa" en terrenos baldíos, repartición de volantes informativos, asistencia a marchas, etc.), algunos vecinos alegan condiciones personales particulares que les impiden participar, aún cuando sus ocupaciones no difieren en demasía de las de los demás. Si bien pudiera parecer trivial, el realizar actos fácilmente identificables con la reivindicación política es un paso muy difícil de dar para los vecinos, pues enfrenta de forma directa su identidad individual. Cómo puede alguien afirmar la completa ineficacia de la política, la total insensibilidad de las autoridades respecto a las demandas $\mathrm{y}$, al mismo tiempo, la necesidad de presionar para combatirlas. Asimismo, hay que considerar que la historia política -en términos amplios la identificación izquierda/derecha de los individuos- es muy divergente; varios entrevistados nos comunicaron el desafío familiar que implica el comprometerse en actividades políticas, sobre todo en familias autodefinidas como de derecha y que ven con malos ojos toda organización reivindicativa.

En este sentido, como muestra Yvon Le Bot respecto al movimiento indígena, la participación política, aún cuando se inserte en un contexto comunitario, siempre porta el impulso modernizante de combate contra la tradición. La subjetivación individual comporta así un cuestionamiento de los roles tanto a nivel familiar (principalmente cuando los miembros son mujeres) como a nivel de la comunidad, ya que participar significa romper con la cotidianeidad pasiva que caracteriza a la mayoría de la sociedad. Significa "afectarse" con aquello que es incapaz de movilizar a los demás.

La politización se expresa, de esta manera, como una ruptura de la continuidad respecto a la comunidad de pertenencia y un cuestionamiento de la identidad individual derivada de los procesos de socialización. La lógica de acción que caracteriza la subjetivación implica así un "distanciamiento y crítica" respecto a los roles que la sociedad le asigna a los individuos. "El sujeto no se da directamente, no aparece más que en la liberación o en el exceso, cuando el actor no es reductible ni a sus roles, ni a sus intereses. El sujeto no es el yo (moi), no es tampoco la identificación de un movimiento social a las leyes naturales y sociales. No se percibe más que en el rechazo de la evidencia de las cosas, en la distancia y la crítica" (Dubet y Wieviorka, 1995: 9). El nuevo "modo de vida" debe ser lo suficientemente atractivo y protector para que la persona decida voluntariamente "devenir vulnerable", es decir, poner en tensión su identidad individual.

El otro problema, íntimamente ligado al primero, es la difícil formación de la nueva comunidad de pertenencia que albergará a los sujetos en formación. Tal como indicamos hace un momento, la politización de las trayectorias individuales implica la adopción de elementos definitorios del colectivo. Así, la "vida digna", tal como los propios actores la imaginan, significa un cambio en sus relaciones individuales, apelando a un sentido de solidaridad que identifican propio de la familia. Es preciso constatar que la condición de allegados muchas veces conlleva la fragmentación de los lazos familiares que van más allá de la familia nuclear. Se puede interpretar, de este modo, la necesidad de la comunidad como la intención de reconstruir, en un horizonte distinto, las relaciones familiares dañadas.

Hay distintos ejemplos que grafican esta demanda por comunidad. Un caso corresponde a María de 36 años, casada con 4 hijos, que vive en una pieza al interior de la casa de sus suegros. El relato de su vida se articula en torno a la necesidad de salir de esa pieza, dados los problemas que se han generado con los dueños de la casa, y darle una nueva vida a sus hijos, más allá incluso de los estudios y de las expectativas de movilidad social. En este contexto, su comportamiento cotidiano parece particularmente patológico, pues tiene una suerte de agorafobia que le impide salir de casa; sin embargo, cada miércoles sale con sus dos hijas más grandes a las reuniones del comité, donde también van su hermana, su cuñado y demás vecinos.

Otro caso es Claudia de 34 años, conviviente y sin hijos, que vive en la casa de sus padres, allegada junto a otros familiares y que ve impedida la posibilidad de tener hijos y construir una familia propia, declara en la entrevista que le encantaría que el comité generara una guardería para los niños donde ella podría ofrecerse como monitora voluntaria.

En ambos casos, el comité se revela para los entrevistados como un espacio comunitario donde es posible desarrollar facetas propias de la personalidad que no son reconocidas al interior de sus hogares. En 
este sentido es que la demanda por vivienda- orientada a superar una necesidad material- se expresa individualmente como una demanda por reconocimiento, es decir, como la lucha por conquistar una identidad lograda- orientada a superar el reconocimiento erróneo (Honneth, 2006b). Por ello, el comité, si bien nace a partir de la articulación de demandas instrumentales equivalentes, mediante el proceso de subjetivación colectiva, deviene en un espacio de resistencia comunitario para las identidades individuales amenazadas.

La difícil formación de esta "comunidad ideal" refiere principalmente a problemas de comunicación, no solamente en un sentido habermasiano (Habermas, 2003) de incapacidad de alcanzar acuerdos, sino también en relación a la dificultad de expresar la "afección" común por la política y la comunidad. En otras palabras, a los vecinos les resulta muy complicado reconocer su falta de reconocimiento, cuando esto significaría el compromiso identitario en la formación del colectivo y, como en el caso anterior, un devenirvulnerable de la personalidad individual (Giddens, 1996).

\section{Devenir militante y política popular}

Como mencionamos anteriormente, la inscripción de un vecino en el comité de vivienda es un dato insuficiente para hablar de un gesto político. El trabajo reivindicativo, que se da al interior del comité, implica una progresiva "afección" política de la subjetividad de los vecinos. Esto significa que la politización de sus trayectorias individuales constituye la interiorización del conflicto que está a la base de sus condiciones sociales, es decir, la incorporación del antagonismo en la interpretación de sus biografías. Chantal Mouffe concibe "lo político como la dimensión de antagonismo que considero constitutiva de las sociedades humanas" (Mouffe, 2007: 16).

Al interpretar los discursos de los distintos miembros del comité, encontramos dos dimensiones centrales que expresan el grado de politización individual, a saber: la pobreza y la centralidad de la lucha. Muchos individuos de origen popular niegan su condición social, esto porque aspiran a conformar parte de la clase media y porque quieren distanciarse de los segmentos de la población más pobres que son beneficiarios de la ayuda social (Angelcos, 2010a; Martínez y Palacios, 1996). Las condiciones de marginalidad y pobreza que los afectan les producen un sentimiento de vergüenza social que les impide acudir a los organismos de asistencia estatal o buscar ayuda solidaria en sus propios vecinos. Sin embargo, pudimos ser testigos de cómo el proceso de subjetivación individual está acompañado de una revalorización de la pobreza, en el sentido que ésta no tiene por qué ser motivo de vergüenza ni de distanciamiento entre los pobladores. Al contrario, puede ser una fuente de identificación individual y colectiva (Chaumont, 2001). Reproducimos textualmente el discurso de una joven pobladora del comité, pues expresa de forma muy clara la subjetivación de la que estamos hablando:

"Nosotros nunca reconocemos que somos pobres, uno piensa que ser pobre es como vivir en la calle, siendo que no tenemos casa, no tenemos una buena educación, pero uno nunca reconoce que uno es pobre, entonces yo creo que me hicieron ver que yo sí soy pobre y yo necesito tener mi casa, necesito educarme, necesito educar a mis hijos, pensar en un futuro, no pensar en una casita, se me abrieron los ojos." (Claudia, 28 años, MPL Franklin).

Al sentirse reconocidos como pobres y parte de un mundo injusto en el que sí hay gente que tiene casa y buena educación, la lucha social deviene un factor central en la proyección de sus vidas. Ya no basta con "padecer" las consecuencias negativas del sistema, ahora es preciso revertirlas.

"Entonces, yo de ellos fui aprendiendo que, ¡no poh!, hay que luchar y hay que ponerle el hombro nomás. Porque nadie va a hacer las cosas por ti y si te caí te volví a levantar. Yo me había inscrito antes para vivienda en SERVIU y era siempre lo mismo, tiene que esperar y yo hacía eso. En cambio conocí a los chiquillos, los fui escuchando, los fui conociendo cómo eran, y que son igual a uno y fui entendiendo cómo realmente pasan las cosas, y por eso me fui convirtiendo de a poquito en dirigente, sacando la voz, tratando de ayudarles y hasta que me gané la confianza de los vecinos, y ellos me eligieron la presidenta del comité de nosotros, el MPL I lo que fue un proceso igual largo." (Sindi, 24 años, proyecto MPL1). 
En fin, pasados nueve meses (abril-diciembre 2010) el proceso de politización del comité y sus integrantes está evolucionando. Personas como Claudia ya han dado ese paso y están dispuestas a seguir con la movilización. Reproducimos también el discurso de Sindi pues ella, al igual que Claudia, no poseía ningún capital político y la orientación de su familia es más bien pinochetista. Sin embargo, al cabo de cinco años de participación en el comité de Peñalolén ha devenido dirigente del proyecto MPL1. Si bien el proceso de politización que hemos estado describiendo no es lineal y no determina que todos los miembros del comité terminen siendo militantes del Movimiento de Pobladores en Lucha sí es un proceso que "afecta" al conjunto de los vecinos y que, eventualmente, pudiera ser un motivo suficiente para iniciar una trayectoria militante.

En este sentido, la comprensión sociológica de la conexión entre trayectorias individuales y politización colectiva nos puede orientar hacia la identificación de un problema central de la política popular, a saber: cómo una minoría politizada es capaz de "afectar" la subjetividad de aquéllos que comparten un conjunto de necesidades objetivas. Esto no debe confundirse con la necesidad de una vanguardia organizada que actuara como conciencia de los "sin conciencia". Más bien lo que se trata es de generar un mecanismo de representación popular capaz de interpretar y dar contenido a aquellos sentimientos pre-políticos no movilizados por el sistema institucional. En términos de Laclau, la política popular debe ser capaz de "nombrar" el conjunto de necesidades y malestares de los individuos convirtiéndolos en demandas susceptibles de ser dirigidas hacia un adversario social, reconstruyendo una fuerza política que incida en las relaciones de poder que dan forma a nuestra sociedad.

\section{Conclusión}

En el presente artículo hemos querido plantear algunos problemas relativos a la política popular en Chile; esto no implica suponer que esa política existe de forma unificada y enfrenta obstáculos definidos, sino entender que "lo popular" tiene una política y que ésta se manifiesta, aún de forma fragmentada, en distintas organizaciones de pobladores en Chile.

Esta idea implica desde ya una problematización del concepto de política, buscando su desplazamiento desde la esfera institucional hacia los ámbitos de producción social. Con esto los límites de la política se vuelven difusos, pero no por ello inexistentes. Tal como plantea Antonio Gramsci "el obrar siempre es un obrar político" (Gramci, 1970: 16), lo que significa que la construcción de una voluntad colectiva implica, al mismo tiempo, la elaboración de un poder contra- hegemónico que cuestiona la dominación imperante. En este sentido, la politización de las trayectorias individuales al interior del comité contribuye a la formación de una fuerza política orientada a subvertir las relaciones de poder existentes.

El comité de vivienda formado por el MPL es un espacio donde los vecinos construyen una comunidad de intereses y se articulan en pos de la construcción de una demanda colectiva. Lo particular de la política popular, ya desde los sesenta, es la combinación de una demanda instrumental con una socialización de corte comunitario, cuestión profundamente estudiada por Rodrigo Baño (1985) en el movimiento de los años ochenta. La articulación entre una subjetivación política individual y una colectiva es la principal apuesta que debe ganar el comité si pretende integrarse a un movimiento más amplio.

Si bien consideramos que las variables estructurales (debilitamiento de la acción sindical, autonomización de los partidos políticos tradicionales, reducción del aparato estatal, hegemonía del mercado, presencia de enclaves autoritarios, etc.) son muy útiles para comprender la desmovilización, nos parecen insuficientes para explicar el nacimiento de una organización colectiva. La pregunta no es, de este modo, por qué individuos que comparten las mismas condiciones sociales no se involucran en una acción política ${ }^{8}$, sino por qué vecinos, ante distintas opciones de acceso a la vivienda, prefieren permanecer en el comité, cuya única promesa es luchar los años que sea necesario para lograr el objetivo, considerando los esfuerzos, decepciones y fracasos que eso implica. Nuestra respuesta es que la politización del comité trae consigo una estrecha articulación entre la definición de una demanda colectiva (darle un "nombre" en el vocabulario de Laclau) y la redefinición de las trayectorias individuales de los distintos miembros. En otras palabras, la política "afecta" a tal punto la identidad de los vecinos que el conflicto y la lucha pasan a ser elementos constitutivos de su personalidad. 


\section{Notas}

* El presente artículo forma parte de mi investigación doctoral en la EHESS de París y fue presentado en el Pre- Alas, VI Congreso chileno de sociología: "Sociología y sociedad en Chile. Escenarios y diálogos contemporáneos", Universidad de Playa Ancha, Universidad de Valparaíso, Chile SOCIORED, Valparaíso, 2011.

${ }^{1}$ Nota Metodológica: El trabajo de campo que da origen a las reflexiones precedentes fue realizado entre los meses de Agosto y Diciembre del año 2010. Agradezco los contactos a Henry Renna del Movimiento de Pobladores en Lucha.

El trabajo de campo consistió en la ejecución de 28 entrevistas en profundidad, ya sea a políticos profesionales, funcionarios públicos, miembros de ONG, dirigentes sociales y militantes de base. En total, 18 fueron realizadas a miembros del Movimiento de Pobladores en Lucha; de las cuales 10 corresponden a integrantes del comité formado en Franklin. Las entrevistas consistieron principalmente historias de vida.

Paralelamente a este trabajo, se realizaron 9 observaciones participantes, de las cuales 6 fueron reuniones del comité de vivienda situado en Franklin.

El análisis de entrevista está en una fase inicial de descripción e interpretación de acuerdo a los procedimientos correspondientes al análisis crítico del discurso teorizado por Teun Van Dijk.

${ }^{2}$ El 20 de diciembre del 2010, la ministra de vivienda Magdalena Matte fue interpelada formalmente ante el parlamento, dada la lentitud e ineficacia de la reconstrucción. (La Nación, 2010)

${ }^{3}$ Esta realidad abre directamente sobre el debate acerca de quiénes son hoy día legítimos habitantes de la ciudad (Bertho, 2005).

${ }^{4}$ Fruto de este trabajo es la elección del concejal Lautaro Guanca, militante del movimiento, en las últimas elecciones municipales.

${ }^{5}$ El proyecto MPL 1, en espera del permiso de edificación, logró una solución habitacional para 32 familias en la población Lo Hermida de Peñalolén. El proyecto habitacional MPL 2, en proceso de construcción, comprende una solución para 120 familias en la población Las Parcelas de la misma comuna. (Corporación Poblar del Movimiento de Pobladores en Lucha, 2011, en proceso de publicación)

${ }^{6}$ Esto no quiere decir que la demanda deje de ser instrumental, sino que se va integrando en un ámbito de significación mucho más amplio.

${ }^{7}$ La UDI, Unión Demócrata Independiente, es el principal partido de derecha en Chile de fuerte ideología conservadora y heredero de la tradición pinochetista. El PPD, Partido Por la Democracia es el tercer partido en importancia de la Concertación de Partidos por la Democracia, coalición de centro izquierda gobernante entre 1990 y 2010, la que está integrada además por la Democracia Cristiana, el Partido Socialista y el Partido Radical Socialdemócrata.

${ }^{8}$ Recordemos nuestro énfasis respecto a que la inscripción en el comité está lejos de ser un acto político, de hecho, esto explica que el número de familias implicadas descendiera de 150 a 30 en un período corto de tiempo.

\section{Bibliografia}

Adorno, T. (2004), Minima Moralia. Reflexiones desde la vida dañada, Akal, Madrid.

Angelcos, N. (2010a), "La estructuración de la subjetividad popular y el problema de la política", Revista de psicología , 19 (2), 55-78.

Ídem (2010b), L'éloignement des 'pobladores' de la politique au Chili. EUE, Sarrebruck.

Ídem (2011), Subjetividad y política. Sobre el rendimiento sociológico de los procesos de subjetivación, Facultad de Ciencias Sociales, Departamento de sociología, Universidad de Chile, Santiago de Chile.

Aranda, C., y Cuevas, J. C. (2008), “Tercera persona plural: la juventud invisible”, Observatorio de juventud, 5 (18), 53- 63.

Baño, R. (1995), “El nuevo carácter del apoliticismo”, Serie estudios políticos N 33, pp. 5- 28, Flacso, Santiago de Chile.

Ídem (1985), Lo social y lo político, Flacso, Santiago de Chile.

Bertho, A. (2005), Penser la "ville monde". Recuperado el 17 de marzo de 2011, de Socio-anthropologie n¹6: http://socio-anthropologie.revues.org/index430.html 
Chaumont, J. M. (2001), “Est- il requis d'être fier pour n'être pas honteux?", en M. Wieviorka, y J. Ohana, La différence culturelle. Une reformulation des débats: Colloque de Cerisy, Balland, Paris.

Desjardins, X. (2008), Le logement social au temps du néolibéralisme. Recuperado el 17 de marzo de 2011, de Métropoles nº 4 http://metropoles.revues.org/3022

Dubet, F. (1994), Sociologie de l'expérience, Éditions du Seuil, Paris.

Dubet, F., y Wieviorka, M. (1995), Penser le sujet. Autour d'Alain Touraine, Fayard, Paris.

Foucault, M. (2008), “De l'amitié comme mode de vie”, en M. Foucault, Dits et écrits. 1976- 1988, Malesherbes, Gallimard, Paris.

Freud, S. (1965), "Rattachement à une action traumatique. L'inconscient", en S. Freud, Introduction à la psychanalyse Payot, Paris.

Giddens, A. (1996), "Modernidad y autoidentidad”, en J. Beriain, Las consecuencias perversas de la modernidad Anthropos, Barcelona.

González, R., Manzi, J., Cortés, F., Torres, D., De Tezanos, P., Aldunate, N., Aravena, M. T., Saiz, J. L. (2005), "Identidad y actitudes políticas en jóvenes universitarios: el desencanto de los que no se identifican políticamente", Revista de ciencia política, $\mathrm{N}^{\circ} 25$ (2), pp 65- 90, Pontificia Universidad Católica, Santiago de Chile.

Gramsci, A. (1970), Introducción a la filosofía de la praxis, Península, Madrid.

Habermas, J. (2003), Teoría de la acción comunicativa, Tauruid, Madrid.

Honneth, A. (2010), La lutte pour la reconnaissance: grammaire morale des conflits sociaux, Cerf, Paris.

Honneth, A. (2006a), La société du mépris, La Découverte, Paris.

Ídem (2006b), "Redistribución como reconocimiento. Respuesta a Nancy Fraser". En N. Fraser, \& A. Honneth, ¿Redistribución o reconocimiento? Morata, Madrid

La Nación (20 de diciembre de 2010), Interpelación a Ministra Matte se centró en reconstrucción. Recuperado el 16 de marzo de 2011, de Diario La Nación: www.lanacion.cl

Laclau, E. (2010), La razón populista, Fondo de Cultura Económica, Buenos Aires.

Martínez, J., y Palacios, M. (1996), Informe sobre la decencia, SUR, Santiago.

Ministerio de Vivienda y Urbanismo. (2010), Propuesta de modificaciones a la política habitacional, Gobierno de Chile, Santiago.

Mouffe, C. (2007), En torno a lo político, Fondo de Cultra Económica, Buenos Aires.

Movimiento de pobladores en lucha (2009), A tomarse Peñalolén para conquistar la ciudad. Recuperado el 15 de Marzo de 2011, de Cuadernos Sur: http://www.sitiosur.cl

Rancière, J. (2007) La Mésentente. Politique et philosophie, Galilée, Paris.

Ruz, L. (2008), "Los jóvenes y su mirada crítica a la democracia en tiempos de cambio", Observatorio de juventud, 5, Instituto Nacional de la Juventud, Gobierno de Chile, Santiago.

Thompson, E. P. (1971), "The moral economy of the English crowd in the eighteenth century", Past \& Present N50, pp. 76-136, Oxford University Press, Oxford.

Toro, S. (2008), "De lo épico a lo cotidiano: jóvenes y generaciones políticas en Chile", Revista de ciencia política, $N^{\circ} 28$ (3), pp. 143- 160. Pontificia Universidad Católica, Santiago de Chile.

Touraine, A., y Khosrokhavar, F. (2000), La recherche de soi. Dialogue sur le sujet, Fayard, Paris. 
Wieviorka, M. (1995), La violence, Hachette littératures, Paris.

Wieviorka, M. (2008), "L’intégration: un concept en difficulté", en Cahiers internationaux de sociologie $\mathrm{N}^{\circ} 125$, pp 221- 240, PUF, Paris

Zúñiga, C. (25 de noviembre de 2010), El "saco sin fondo" del déficit habitacional: 900 mil familias sin casa en Chile. Recuperado el 16 de marzo de 2011, de Radio Universidad de Chile: www.radio.uchile.cl

Recibido: 01.09.2011

Aceptado: 11.03.2012 